\title{
Transactional, Cooperative, and Communal: Relating the Structure of Engineering Engagement Programs with the Nature of Partnerships
}

\author{
Julia D. Thompson \\ San Jose State University
}

\author{
Brent K. Jesiek \\ Purdue University
}

\begin{abstract}
This paper examines how the structural features of engineering engagement programs (EEPs) are related to the nature of their service-learning partnerships. "Structure" refers to formal and informal models, processes, and operations adopted or used to describe engagement programs, while "nature" signifies the quality of interactions or interpersonal dynamics within partnerships. We developed the Transactional, Cooperative, and Communal $(T C C)$ framework to code interviews $(N=30)$ with community partners, administrators, faculty members, and students at three well-developed and geographically-diverse EEPs. A thematic analysis approach was then employed to relate the three TCC partnership natures to six emergent structural themes: (a) program purposes, (b) partnership structures, (c) modes of interactions, $(d)$ organizational partners, $(e)$ individual partners and advisors, and $(f)$ projects. The paper concludes by discussing specific implications of the TCC framework for educators and program administrators, the importance of recognizing both individual and organizational influences on partnerships, and the salience of engineering education as a context for service-learning and community engagement (SLCE) programs.
\end{abstract}

\section{"When you have seen one partnership, you have seen one partnership." \\ - Holland \& Gelmon, 1998}

Service-learning partnerships are highly contextual and linked to a host of structural factors, including the type of university, program mission(s), institutional capacity(ies), and specific challenges faced by the partner community (Holland \& Gelmon, 1998). The complexity and importance of these factors is further accentuated by how partnerships, as units of analysis, are articulated and investigated in the service-learning field. Bringle and Hatcher (2002) first proposed examining partnerships in terms of individual relationships and have argued for use of the term "partnerships" to describe interpersonal relationships with varying degrees of equity, closeness, and care (Bringle \& Hatcher, 2012; Clayton, Bringle, Senor, Huq, \& Morrison, 2010; Jacoby, 2012). Alternatively, Janke (2009, 2012) and Giles and Elyer (2013) suggest analyzing partnerships in terms of organizational structure, asserting that individual relationships as a unit of analysis discount the organizational influences present in the partnerships. Organizations tend to rely on prescribed procedures, roles and responsibilities, and maintain distinct institutional identities within partnerships (Janke, 2012; Simon, 1991). In this paper, partnership refers to individuals or organizations that work together for an intended mutual benefit, thereby recognizing potential influences at both the individual and organizational levels.

Additional research on the nature of partnerships has also identified important trends concerning the quality of interpersonal and intergroup dynamics within and among partnerships (Clayton et. al. 2010; Dorado \& Giles, 2004; Enos \& Morton, 2003; Phillip \& Ward, 2009; Sockett, 1998;Vanasupa \& Schlemer, 2014). For example, Enos and Morton (2003) developed a theoretical framework examining the nature of partnerships by proposing two fundamental types: transactional and transformative. Transactional partnerships focus on wellarticulated, short-term activities and interactions that provide benefits for each group, while transformative partnerships appear less well defined and may enable new opportunities and relationships to emerge.

However, few studies have attempted to systematically relate structural factors to the nature of service-learning partnerships. Notable exceptions include work by Dorado, Giles, and Welch (2009) examining how the structural element of delegation, where a person outside of the partnerships coordinates the service experience, can help establish partnerships but limit the potential outcomes 
of partnership development. Additionally, Clayton et al. (2010) designed an assessment tool to study faculty experiences of "closeness" in partnerships based on the frequency and diversity of interactions, along with reciprocal influences on decisionmaking. They grounded their work in a model that describes service-learning partnerships as a network of discrete relationships among Students, Organizations, Faculty members, Administrators, and Residents (SOFAR) (Bringle et al., 2009). Additionally, Clayton et al. (2010)'s study of servicelearning and civic engagement relationships leveraged the SOFAR model, Enos and Morton's (2003) aforementioned concept of transactional and transformative partnerships, and Mashek, Cannaday, and Tangney's (2007) approach to measuring perceived degree of closeness in a relation through the use of overlapping Venn diagrams. Clayton et al. (2010) found that indicators of "closeness" between faculty and community were positively correlated with other measures reflecting the transformational nature of these same relationships.

This study builds on and advances research on service-learning partnerships by answering the research question, "How do structural factors relate to the nature of partnerships, particularly in engineering education contexts?" In this paper, "structure" refers to formal and informal models, processes, and operations associated with a given program, while "nature" refers to the quality of interactions or interpersonal dynamics in those partnerships. The following section provides a further overview of models for, and studies of, engagement programs in engineering education settings.

\section{Structure of Engineering Engagement Programs}

In the last two decades there has been an upsurge in engineering service-learning and community engagement programs, referred to in this paper as Engineering Engagement Programs (EEPs), at many U.S. engineering schools (Bielefeldt, Paterson, \& Swan, 2009). EEPs may include curricular and/ or co-curricular engagement. Numerous thought leaders and researchers see service-learning as a pedagogical method that can support the need to prepare future engineering professionals for an increasingly interconnected and technologically advanced world (National Academy of Engineering, 2005; Sheppard, Macatangay, Colby, \& Sillivan, 2009; Shuman, Besterfield-Sacre, \& McGourty, 2005). Additionally, there is evidence of a growing desire among engineering students, professionals, and faculty to serve communities both locally and globally, often reflecting their personal and/or pro- fessional commitments to service, social responsibility, social justice, and related aspirations (Litchfeild \& Javernick-Wills, 2015; Lucena, Schneider, \& Leydens, 2010).

The service component in EEPs is often based on project-based learning (PBL) (Bielefeldt, Paterson, \& Swan, 2010), where the educational experience is student-centered and the final outcome is a specific solution or "product," such as a project report, design solution, and/or actual physical object (de Graff \& Kolmos, 2007). The outcomes from such projects are intended to address a specific need of the partnering organization or community while advancing student learning. However, critiques of engineering service projects, particularly when done in a global development context, have highlighted that these projects often focus too heavily on technical aspects and student learning; disregard critical issues of cultural difference, social power, structural constraints, and sustainability; and reinforce underlying neo-liberal and neo-colonial tendencies (Nieusman \& Riley, 2010; Schnieder, Lucena \& Leydens, 2009).

To date, research on EEPs has tended to follow the path established by the broader literature on service-learning and community engagement in higher education, focusing mainly on student outcomes and with minimal attention to partnerships or the perspective of partner communities (Bielefeldt, Paterson, \& Swan, 2009; Giles \& Elyer, 1998;). Notable exceptions include research that explores partnerships through a faculty lens (Tucker et al., 2013; Vanasupa, Schlemer, Burton, Brogno, Hendrix, \& MacDougall, 2014) as well as research on community outcomes from the perspective of community members participating in an engineering service project (Reynolds, 2014).

For the purposes of this study, the authors reviewed research on partnerships within the broader service-learning literature to advance investigation of partnerships in an engineering context. The following section synthesizes research on the nature of partnerships.

\section{Nature of Community Engagement Partnerships and the TCC Framework}

A number of studies categorize interpersonal and intergroup dynamics within and among partnerships (Clayton et. al., 2010, Dorado \& Giles, 2004; Enos \& Morton, 2003; Feinstein \& Meshoulam, 2014; Phillip \& Ward, 2009; Sockett, 1998; Vanasupa \& Schlemer, 2014). There are many similarities among these categorizations, specifically with regard to the boundary between the program and the community. These similarities, synthesized 
below, recognize that some partnerships create distinct boundaries between partnering organizations (Transactional), some partnerships involve intentionally working together (Cooperative), and others involve deeper and more fluid partnerships that are grounded in common values (Communal).

The transactional category indicates a distinct boundary between stakeholders, thereby tending to preserve or enhance a sense of "us" and "them" between the participant groups. This type of partnership is reflected in Feinstein and Meshoulam's (2014) notion of "client logic," where staff at Informal Science Education (ISE) centers "tended to see themselves and their colleagues as a coherent 'us' separated by institutional barriers from the less distinct 'them' of the surrounding community" (p. 386). This category is also linked to Sockett's (1998) description of service and exchange-related activities, where service relationships offer support for institution-related functions, and exchange relationships occur when there is a give-and-take of resources for mutual benefit. Enos and Morton (2003) similarly frame transactional partnerships as " instrumental, designed to complete a task with no greater plan or promise. The parties engage together because each has something the other finds useful" (p. 24).

A subcategory of the transactional category is "unilateral." This category also involves distinct boundaries between stakeholders, but unilateraltransactional activities are one-sided, such that only one side of the partnership benefits from the interaction or activity. When a significant amount of interactions and activities are done unilaterally, the partnership can additionally be described using Clayton et al.'s (2010) notion of "exploitative" relationships, where the relationship is "so unilateral that, intentionally or unintentionally, they take advantage of or harm one or both parties" (p. 8). The degree of unilateral-transactional activities can vary considerably, ranging from instances of miscommunication that are easily corrected to something as severe as an intentional exploitation of community members or university students.

The cooperative category focuses on interactions and activities where the ownership and development of programs is shared, and the lines between "us" and "them" are intentionally blurred as communities and university programs work together. This category is associated with Feinstein and Meshoulam's (2014) notion of "cooperative logic," where university programs actively recruit from and engage with a community, co-create the program with community members and organizations, and build capacity within the community rather than acting as an external expert. This category also relates to Sockett's (1998) definition of "cooperative relationships," where there is recognition that each partner has unique knowledge and "plan together and share responsibilities" (p. 77).

In the communal category, partnership boundaries are permeable and transcend the participating groups to include the community and/or the society as a whole. This category is connected to Enos and Morton's (2003) notion of "transformational relationships," where partnerships "proceed with less definition, with an openness to unanticipated developments ... here, there is an expectation that things may change, that the order may be disturbed, and that new relationships, identities, and values may emerge" (p. 24). It also relates to Vanasupa and Schlemer's (2014) concept of "collaborative co-creating partnerships" where "participants [are] committed to a larger set of shared commitments, such as the long-term well-being of a community. The tasks that are completed are done so with a priority placed on the social value" (p. 6). Also relevant to the communal category is Sockett's (1998) notion of "systematic and transformational relationships" where "parties share responsibilities for planning, decision-making, funding, operations, and evaluation of activities, and in which each institution is transformed through the relationship" (p. 76). We adopt the term "communal" rather than "transformational" in order to focus on the boundary characteristics and dynamics in partnerships rather than the personal and institutional changes that may occur as outcomes.

Similar to the paths of engagement described by Dorado and Giles (2004), the categories of the TCC framework are dependent on structural elements of the program and can vary over time. They are not intended to be progressive or value-laden, and partnerships may have interactions that reflect more than one nature within a given partnership at any given time or over time. The three categories transactional, cooperative, and communal - are intended to provide a useful framework or vocabulary to describe and discuss the nature of interactions, language, and activities within partnerships.

\section{Method}

This study was part of a larger dissertation that also examined the motivations of individuals and organizations within EEPs, as well as the role of projects within partnerships (Thompson, 2015). The study utilized an explanatory, multi-site, qualitative case study approach (Yin, 2002). The case study approach allows for the investigation of complex phenomena by including and preserving the context of the phenomena. This is particularly 
important for the study of service-learning and other community engagement partnerships, since the program structures are interconnected and unique for individual programs and partnerships. The sections that follow first describe the three EEPs and study participants, as well as the data analysis procedures, which combined typological and interpretive approaches (Hatch, 2002). All data was collected following appropriate procedures for interacting with human subjects and was approved by Purdue's Institutional Review Board.

\section{Description of the EEPs}

This study examines partnerships at three welldeveloped EEPs, namely Engineering Programs In Community Service (EPICS) at Purdue University (Coyle, Jamieson, \& Oakes, 2005), Community Playground Project (CPP) at Louisiana State University (LSU; Lima, 2013), and Global Project Program - United States project centers (GPP-US) at Worcester Polytechnic Institution (WPI; Vaz, 2011). The programs and partnerships included in this study were selected based on the following criteria: engineering undergraduate students involved in project-based curricular experiences, student participation counts toward their degree requirements, the partnership involves a nonprofit or governmental organization, the specific partnerships under investigated had a history of more than three semesters, and the EEP had been in existence for at least 10 years. It is worth noting that the GPPUS does not identify as a service-learning program since it does not emphasize the service component and work with a variety of partners, including forprofit agencies. For consistency, however, we only studied their partnerships involving nonprofit and governmental agencies.

To identify similarities and differences across the three programs we utilized McCahan et al.'s 12 dimensions for characterizing service-learning in engineering (see Appendix A; McCahan et al., 2012; Thompson, 2015). The main similarities we found among the three EEPs are the rigor and alignment of learning outcomes and assessment as well as the long-term status of the respective partnerships. The main differences we found among the programs include the number of participating students, extent of integration with the students' respective curricula, types of student deliverables, and types of interactions with partner organizations and communities.

Purdue University's EPICS program involves vertically integrated teams - first- to senior-year students work together. The program is open to all majors with approximately 800 students participating annually. Students register for the course as an elective or to meet other curricular requirements as outlined by their respective degree program. The EPICS students work on technical engineeringcentered projects, such as building a kiosk for a local science museum or developing a software application for a local government agency. Each team directs the frequency and type of contact with the partnering organizations, and there are two formal design reviews during the semester where teams get feedback on their work.

An advisor, mentoring each team, is typically a faculty member or other individual with relevant expertise in the subject domain. Two partners interviewed for this project were also in the dual role of team advisor and representative of the partner organization.

LSU's CPP program involves approximately 85 students in three sections of a first-year biological engineering course focused on designing and building playgrounds for local, public elementary schools. These public schools disproportionally serve low-income and black students and typically lack adequate funding for playgrounds. The CPP is the main means by which most public schools in Baton Rouge have playgrounds. In the CPP, the university students go to the elementary school at the beginning of each semester to partner as a math or reading buddy with an elementary student and discuss their playtime activities. This addresses another need of the schools - to provide tutoring support for the elementary students - while the university students simultaneously benefit from developing deeper relationship with the elementary students and learning about how they understand and experience play. The university students who develop a relationship with the community may also be asked to continue on within a design team. The design teams are organized and working on an ongoing basis, and are responsible for securing funding, finalizing designs based on the university students' work, and carrying out the playground builds.

WPI's GPP has approximately 500 students from a variety of majors (about half are engineers) who, in their junior year, are accepted into the program and paired with centers around the world. In this research, we specifically included the centers located within the Eastern United States, and refer to this portion of the program as GPP-US. The students take a seven-week preparation course, where they research the host organization, learn social science techniques, and prepare for their project work. The students then spend another seven weeks working onsite at the partner organizations. GPP-US projects are social science-oriented with a focus on integrating technological and social considerations. For example, they may work on an environmental 
action plan for a city government by interviewing community residents and writing up a proposal.

\section{Participants}

Individual participants for this study were identified based on their length of time in the respective programs (i.e., at least three terms) and/ or dedication to the program, as recommended by the program administrators and faculty members. Participants were identified in two categories: Program Affiliates and Partners. The Program Affiliates $(n=14)$ included 7 faculty members/advisors, 2 partner-advisors, 2 former students, and 3 EEP program administrators. The Partners $(n=16)$ included individuals working within the partnering community organizations, such as a manager of a community clinic and an elementary school principal. In the case of the EPICS program, we originally categorized the partner-advisors as Partners; however, subsequent analysis suggested that the partner-advisors were more appropriately categorized as Program Affiliates since their motivations were similar to other Program Affiliates (Thompson, 2015). Two former students, one from EPICS and one from CPP, were also included as subjects for this study since they had extensive experience with the partnerships in light of continuing engagement after graduation - one as a professional engineer and the other as a graduate student.

A total of 31 semi-structured interviews were conducted for this study, with 30 interviews analyzed and reported on. One interview was not included in the analysis due to a substantial time lapse between the interviewee's participation in the program and the interview. Additionally, two other participants asked to be interviewed together, with the resulting transcript analyzed as a single interview.

\section{Interview Protocol}

The interview protocol (see Appendix B) was designed for the first author's dissertation, which also investigated the motivations of individuals and organizations involved in the engagement partnerships. The interview questions were in part based on findings from other research on community-university relationships (Sandy \& Holland, 2006; Stoecker \& Tryon, 2009; Worrall, 2007), and informed by discussions with administrators in each of the three programs. The typical length of interviews ranged from 45 to 90 minutes. Interview transcripts and associated results of data analysis were sent for review and member checking by each respective participant, with all resulting clarifications and edits integrated into the transcripts. The first author also triangulated information from the interviews with informal program observations (e.g., sitting in on design meetings and going to community sites with students), discussions with program administrators, review and analysis of program publications and program documentation (e.g. contracts written for the partnerships, diagrams of the engineering design cycle for student projects). For example, many of the specific program policies described by the participants were articulated within policy documentation and publications.

\section{Data Analysis}

Data analysis was carried out using a combination of typological and interpretive analyses as outlined by Hatch (2002), with close attention to methods for trustworthiness in qualitative research (Shenton, 2004). The initial analysis of the GPPUS interviews attempted to relate the partnerships to the 2-dimensional framework (representing partnership type and extent) proposed by Phillips and Ward (2009). However, the initial analysis resulted in the bifurcation of data, with multiple partnerships characterized by both the static and the transformative stages - opposite sides of a progressive dimension (Thompson, 2015). For example, transformative dynamics were reflected in students sharing the knowledge they have gained with the partner organizations and broader community. Yet the very same partnerships did not have any feedback mechanism to enable the partner to shape the student learning outcomes, which was evidence of a static dynamic. This tension suggested to us that it was more appropriate and effective to examine specific interactions, activities, and language within a partnership rather than categorizing the whole partnerships using the Phillips and Ward framework. As a result, the authors went back to the literature and compiled research focused on the boundary between the programs and the community to establish the TCC framework.

The interactions, activities, and language within all the interviews were coded with the TCC framework using the Dedoose (2015) software. In accordance with the interpretive approach, the first author searched for salient interpretations of the relationships between the nature of interactions and the structural components that became the emergent themes (Hatch, 2002). This information was then reviewed and revised through consultation with the second author and other members of the first author's dissertation committee. The interviews were also re-read to search for counter-examples, and results were then written up for each of the three programs. 
The reports on each program were shared with a corresponding administrator for verification; all reports were revised based on their feedback.

The first author re-read the summary reports, keeping this study's research question in mind: how does the structure of the program relate to the nature of the partnership? An intentional effort was made to search for commonalities and differences among the three programs (Patton, 2002). Many of the findings overlapped well across the three programs and offered more depth to the structural themes. The themes were then revised to encompass all of the programmatic outcomes, highlighting both differences and commonalities across the three programs.

\section{Trustworthiness}

This research study integrated practices to improve the trustworthiness of findings. Guba (1981) proposed four criteria for rigorous qualitative research: credibility, transferability, dependability, and conformability. Shenton (2004) linked these four criteria to research methods and study design. Within this study, all four of the criteria were met. Credibility was addressed by recruiting research participants through trusted individuals in each program, triangulating findings across participants, discussing the research design with colleagues and mentors, searching for contradicting themes in the analysis, providing the transcripts and interpretations to the participants for review, and describing the findings within the context of other research as appropriate. Transferability was addressed through the number of participants $(N=30)$, including three regions within the United States, variation in types of community partner organizations under investigation, the number and length of data collection sessions, and the time period of the data collection (Spring 2011 to Spring 2014). There are limitations to transferability as the focus of this study was on curricular engineering engagement partnerships in a domestic context. Dependability, which is connected to rationale and consistency of the research approaches, was met by articulating the research approaches, establishing a clear rationale for using these approaches, and grounding the steps in previous studies. The final criterion, conformability, ensures that the findings reflect the experiences and ideas of the participants and not the preferences of the researcher. This was done through triangulation, minimizing and articulating the shortcomings of the study methods, member checking, and reporting in-depth research methods. More detail about the methods can be found in the first author's dissertation (Thompson, 2015).

\section{Findings}

Six structural themes were identified that influenced the nature of interactions within the partnerships: (a) program purposes, (b) partnership structures, (c) modes of interactions, (d) organizational partners, (e) individual partners and advisors, and (f) projects. While each is discussed in turn, it is worth emphasizing that the themes are intertwined since program purposes and partnership structures directly impact the modes of interactions, the types of organizational partners, the individuals involved, and the types of projects undertaken.

\section{Program Purposes}

The first structural theme focuses on the objectives, goals, and purposes stated in the program literatures and expressed by the participants. Participants described the purpose through transactional, cooperative, and communal lenses. The transactional purpose focused on the exchange of an educational experience by the students for some benefit to the partnering organization. For example, one partner described the financial benefit of the project: "It's a great [monetary] deal. So it's a good deal for [GPP-US], it's a great deal for the students to actually have something [to show] that has meaning to it." This partner emphasized the exchange quality of the partnership, which has a financial benefit for the organization while providing meaningful educational experiences for the students.

Cooperative purposes focus on the relational component that forms through the engagement. For example, one partnering organization was a professional healthcare program that oversaw an oncampus community clinic. The students associated with this professional school worked alongside the engineering students. Many projects the students worked on involved designing and building demonstration equipment for the school and the clinic. An important objective, as identified by the partner, was focused on the relationship and collaborative experiences between the professional healthcare and engineering students. This partnership had increased the program's credibility by giving their graduates an advantage, as it was seen to "stretch [the students] in terms of communication and learning the design process."

Communal purposes focused on community building or unity as a goal of the engagement. For example, the founding faculty member for the CPP program indicated that its original purpose was primarily focused on building playgrounds and educating the undergraduate students, largely in transactional terms. But as she explained, Hur- 
ricane Katrina resulted in greater emphasis on the community: "I don't think I even realized I was part of a trench, of a community tribe, if you will, until [Hurricane Katrina]. And how important it was, how important [the trench] was for people impacted and for people [in Baton Rouge]." Since Katrina, the purpose of the CPP shifted to a more communal nature, and this was represented in the mission statement, program structure, and syllabus of the class. For example, teaching design was presented as designing for the soul of the community, which focused on the importance of reflecting the community dynamics within the playground design. The online mission statement of the CPP similarly emphasizes community: "LSU faculty, staff, and students have worked alongside their community partners to address the community needs, demonstrating a commitment to work with the community, rather than simply providing a product for the community" (CPP, 2014).

\section{Partnership Structures}

The second structural theme focuses on the partnership structures. Two overarching partnership structures were identified in this study, one where the institutional influences were dominant and there were systematic procedures and roles for participants, and the other where the individual relationships were dominant and the procedures were more malleable and dependent on context and personal networks. All the programs had institutional and individual influences on partnerships, yet the level of influence on the partnerships varied considerably.

The partnerships within the EPICS and GPP-US programs primarily corresponded with the institutional influences, as reflected in their use of project cycles with clear procedural steps and prescribed roles for participants. Evidence for this tendency was found in the interviews and confirmed through publications (Coyle, Jamieson, \& Oakes, 2005; Vaz, 2011) and policy documents, e.g., partner contracts and course syllabi. More specifically, each of the defined project stages often had an intended partnership nature. For example, both programs had a project identification stage where the partner would work with the program staff, and possibly students, to identify appropriate projects in terms of meeting the educational requirements of the students and providing a value to the partnering organization. This phase was intended to be cooperative, as the parties picked a project together. Yet there was evidence of times when the interactions veered from the intended natures. For instances, one advisor described a situation were a partner approached him and said that the project was not meeting the needs of their organization - the project was too large in scope and they wanted smaller projects. This reflects a unilateral-transactional interaction, i.e., the students were gaining an educational experience yet the project was not beneficial for the organization. The advisor was then able to refocus the project to better align with the needs of the partnering organization.

In the CPP, the structure and process associated with building a playground was malleable from site to site and depended on an evolving network of personal relationships to complete each project (Lima, 2013). For example, one partner described receiving a small grant for the playground, and the faculty member assisted by leveraging her network:

The money that we received for our playground, it wasn't very much ... but [the faculty member] knows the people in the office that works with school systems so she was able to say, "Look, I know that they set aside money for the mulch, call this person. Well, better yet, let me talk to them." So, she was able to get the school system to put in.

In this instance, the faculty member was able to get supplementary funding, and a listserv of community members and volunteers was available to request donations as needed. Leveraging networks in this manner allows for both cooperative and communal interactions to emerge as different groups work together to overcome a challenge (cooperative) and rely on and enrich relationships with the broader community (communal). As the following sections indicate, the nature of the partnerships is often further affected by other characteristics and preferences at both the individual and group level, not to mention the types of projects themselves.

\section{Modes of Interactions}

The third structural theme focuses on transactional, cooperative and communal modes of interaction. For each of the three EEPs, there was evidence of a variety of the three modes. Transactional interactions often occurred when there were clear boundaries around different roles or separation by physical distance. During these times, individuals or groups worked independently or within specified roles, and the approaches taken were often used for appropriateness, ease, or urgency. Cooperative modes of interaction allowed participant groups to work together and provide opportunities for participants to be involved in decision-making. The communal modes of interaction were focused on relationship- and community-building, and allowed participation from the wider community. For ex- 
ample, one partner responsible for landscape maintenance describes how he incorporated the three modes of interaction during the various stages of a project:

[My organization is] tasked to do a yearly inspection of [the elementary schools'] playgrounds. Assess the condition, the age, the usability, and the life expectancy of each individual unit. And then I would put together a ranking of those sites that had units or did not have units. And each year I would forward that ranking to [the faculty member]. And she would do some fundraising, and we were able to get funding. Then we would put our resources together and our volunteers together to install playgrounds.

A transactional mode of interaction is reflected in this partner's ranking of the schools and providing a list to the faculty member, as this task was done independently of the partner to make the process easier and leverage the community partner's specific knowledge. A cooperative mode is reflected when the community partner works with the faculty member to mobilize resources, as this step involves multiple parties. Finally, the partner reflects a communal mode when describing the playground build, since the installation is a community-building activity.

\section{Organizational Partners}

The fourth theme examines how the partner organizations influence the nature of the servicelearning partnership. Partner organizations bring their own cultures and missions into the partnership. Organizations driven by monetary concerns, or that are highly bureaucratic, are likely to reinforce the boundaries between the different participant groups. This dynamic leads to transactional interactions and activities. Those organizations that rely on partnerships to function or focus on building community tend to blur the boundaries between participant groups and create ways to involve all participants in the functioning of the organization. This blurring of boundaries leads to cooperative and communal activities and interactions.

Within some organizations, establishing and maintaining a transactional dynamic is beneficial and leads to successful outcomes. For instance, one partner of the GPP-US program explained how the outsider status of students actually resulted in a successful project:

Success on [that project] was that it validated [the data], because we have a fairly strong union here, and having to get a third party inde- pendent of management that came in and said, 'Hey, this is what your marketing unit members said during the surveys and so forth.' ... It gives us ability to move forward.

In this situation, the transactional dynamic and clear boundaries within the partnership improved the validity of the outcomes, as the students were seen as a separate entity from the union and management.

On the other hand, organizations that focus on building relationships as a central dimension of their operations tended to have or create pathways to better integrate the participating university students. For instance, one partner of the EPICS program described their organization using a "hitchhiking" metaphor: "[The organization] is kind of like hitchhiking: you have a need and you put your thumb out - whoever picks you up, so to speak, you ride with them as long as you can." This openness allows partnerships to emerge, and have greater influence on the function and direction of the organization. This organization also had many students volunteering outside of the service-learning course, and thus students could start personally identifying with this organization.

Another organization, a community clinic working with GPP, had the students perform an IT assessment. This organization tended to have a communal approach, as they regularly employed members of the community they were serving, and they focused on a chronic illness that disproportionately impacts disenfranchised members of the community. These partners integrated the students into their work environment, and talked at length about the personal and on-going relationships with the students and advisors.

Overall, the EEPs had varying types of agencies with whom they partnered. The nature of interactions within each of the partnerships was influenced by the partnering organization, especially if the organizations had well-established cultures. Yet as the following section indicates, individuals as well as organizations can significantly influence the nature of the partnerships.

\section{Individual Partners and Advisors}

The fifth theme explores the influences of individual partners and advisors. The manner in which individuals influence partnerships varied among the different partnership structures, with similarities among EPICS and GPP-US, which in turn differed from the CPP. Thus, this theme is split into two sub-themes, individuals within EPICS and GPP-US and individuals within CPP. (Further 
discussion regarding the nature of these differences is also presented in the Discussion section of this article.)

Individuals in EPICS and GPP-US. The EPICS and GPP-US programs have well-established roles and procedures. In these two programs, the partners and the advisors were well aware of program expectations and the abilities of students, and were personally invested in the projects. Nonetheless, some individuals tended to prefer partnerships with a certain nature. In EPICS, one advisor focused on the cooperative interactions with the goal of creating a "think-tank" atmosphere, and emphasized both student learning and his own. In contrast, another advisor in EPICS stressed the importance of boundaries. As he explained, "I really want to stay in that advisor role and not become the design leader, because that really oversteps the boundaries." This approach promoted a more transactional nature, as it established clear boundaries between participant groups.

An individual can also create an unsuccessful environment when they do not properly and adequately engage with the project and associated relationships. One partner in GPP-US described one advisor as being "hands-off" when the students needed guidance; as a result, the final project did not adequately support the organization's needs.

Individuals in the CPP. The CPP is more reliant on individual relationships and therefore depends on the dedication of key individuals within the partnerships for project success. A faculty member recognized this dedication as a "critical mass of people who are committed and bought in." As a reflection of this observation, all but one of the interviewees showed extreme dedication to CPP, the projects, and the associated personal relationships. These individuals harness their own skill sets, and often went out of their comfort zone to assist in the projects. The resulting interactions and activities were often categorized as cooperative and/or communal. For example, one partner described the project as her dream:

I [used to go] to playgrounds just to look at them and compare them ... to see what's fun, and I was always dreaming of a little playground and what it would be. . . I was able to get some [other groups] to do projects and they bought into it big time... I had a little dream, but with the community's help, it became a big dream. And so, it's like a dream come true because it's happening.

The partner was able to harness CPP and other community groups to achieve their own aspiration: to bring a playground to their students. Through their dedication and personal relationships, this partner was able to create cooperative and communal exchanges that ultimately resulted in a playground.

Yet not all the partners had the same level of dedication and focus on relationships within the CPP program. One of the interviewed participants was not as personally invested. The elementary students contributed to decisions about the colors and types of equipment, and the principal focused on the physical playground being the main motivation of the partnership. During the playground builds, the participant provided the volunteer crew some food and refreshments. When asked if the project was more transactional or transformative, she described the relationship as a transactional exchange: "it's good for our children and our kids need that ... And [the faculty member] teaches the [LSU University students] how to write the grants and how to go solicit to get the money and all that kind of stuff." Ultimately, this project was a success, in terms of project completion and installing a playground.

Overall, the individuals' approaches, experiences, levels of dedication, and unique personalities influence the nature of the partnerships. Some might enjoy and create cooperative educational experiences; others will promote relationships with a more transactional nature. There are also likely to be some individuals who are not as invested in the programs. The next section turns to another factor revealing how the projects themselves are linked to the nature of partnerships.

\section{Projects}

A sixth and final theme highlights how the assignments and deliverable influenced the nature of the interactions. The engagement projects in these programs were often focused on a need that was recognized by a partner organization but went beyond the organization's scope and ability to address. For example, an elementary school does not regularly design playgrounds, and the children of the school were in need of the playgrounds. We identified three specific characteristics of the projects that influenced the nature of partnerships: the student-partner relationship, project constraints, and the problem-solving method.

The transactional examples tended to keep each group of constituents distinct, and involved welldefined problems. Students often worked independently, or required feedback from partners at specific times. The constraints of a project were well defined in terms of need and scope. The problemsolving approach is systematic and clearly articulated through class materials. Unsuccessful transactional projects were typically viewed as not useful by the 
organization, often because students made incorrect assumptions about the community or they worked on projects that were inappropriately defined.

The projects that resulted in cooperative interactions were more likely to have students spending time integrated into and/or working closely with the organization. These types of projects were often focused on increasing the capacity or capabilities of the partnering organization, and demanded critical thinking and reflection as the students and/or advisors engaged with the partners. The unsuccessful cooperative projects were most often stopped because of ethical issues, such as an organization asking students to go against IRB protocols.

In the communal projects all constituents (i.e., students, community members, volunteers, faculty members, etc.) were seen as part of, or connected to, the larger community. The projects addressed a socially just cause while engaging personal passions, and the design process itself built a sense of unity among the constituents. An unsuccessful element of the projects focused on the inability of the projects to address the root cause of the target issue. For example, there was recognition by participants that inequality existed in the funding of public schools systems, an issue which the CPP was not directly addressing. Nonetheless, there was also concern that a long-lasting political solution may not be currently viable, and there was confidence among the participants that the immediate need of providing playgrounds was possible.

\section{Discussion}

In this research study, we identified six structural themes that influenced the nature of partnerships in three EEPs. In the remainder of this section we further reflect on the application of the TCC framework, elaborate on how Inter-Organizational Relationships (IOR) differ from Individual Relationships (IR), and offer an expanded discussion of the study's unique impact on EEPs. In doing so, we identify how this study contributes to the servicelearning literature by drawing on and providing further validation of categories of service-learning partnerships through the TCC framework, and explicitly link the partnership categories to program structures in the context of EEPs.

\section{TCC Framework: Reflection and Implications}

This study draws on previous research on the nature of service-learning partnerships and organizational logic to create the TCC framework, which was in turn used to analyze specific interactions, activities, and language used to describe the partner- ships investigated in this study. By using the TCC framework to examine structural features, we were able to identify how these larger partnership trends appear within specific interactions in the context of EEPs. By highlighting both the TCC framework and the structural elements, we aim to motivate EEP leaders and administrators to reflect on and more clearly articulate the types of community partnerships they would like to develop.

Through the course of our study and in related conversations and literature, one specific topic that frequently emerged centers on the question: "Which approach is best?" Indeed, many see cooperative or communal as something to strive for, as reflected in Jacoby's notion of reciprocity (Jacoby, 1996, 2003). As Jacoby argues, reciprocity implies an effort to move beyond notions of charity and toward the elimination of a need within a community, and with all participants viewed as both learners and teachers. It would be difficult for transactional partnerships to meet this definition of reciprocity, since the objective of the partnership is to work on a specific need, and the boundaries between learner, teacher, and community are intentionally maintained. However, we suggest that reciprocity varies according to the nature of the partnership so long as the partnerships are grounded in equity and respect. This can be accomplished - or fail - within partnerships of every type. The goal of the servicelearning educator or administrator is not to strive for a specific nature, but to reflect on and assess the philosophy and intentions of a program and/or project and align these considerations with one or more appropriate TCC approaches.

More specifically, transactional interactions tend to separate the community from the program and its students. In the context of a given project, the program strives to provide a solution or product identified for or by the community, and the interactions, activities, and language reflect a dyadic relationship. Reciprocity in the transactional context focuses on the partnerships meeting the desired needs of all constituents. The most common example is a need identified by the community, with the students learning as they address this need. When a transactional relationship is done well, all constituents are valued and respected within the partnership while having clear roles and responsibilities among the participant groups. The benefits of such partnerships potentially include greater consistency, scalability, durability, efficiency, and a lower time commitment. Feinstein and Meshoulam (2014) additionally highlight the benefits of transactional strategies (or "client logic") to "offer more efficient ways to address particular well-known and deeply entrenched problems" and "protect and enhance the 
things that make a particular [Informal Science Education (ISE)] organization interesting and unusual" (p. 389). Yet when a transactional relationship is done poorly, the relationship becomes detrimentally one-sided. One partner will make incorrect assumptions about and/or disregard the needs of the other, or in more extreme cases even exploit the other partner for their own benefit.

The cooperative relationship involves the program members (i.e., students, advisors, and administrators) working with the partner (i.e., community partner, sponsor, and/or intended end users) as a single team. There may be distinct roles and responsibilities, yet there is an intention to work as a cohesive whole. There is more of a "we" mentality that requires the community and program to work closely together. Reciprocity in such relationships focuses on the process as well as the product. The partnership needs to be adaptable to the community, and the community's input needs to be included in the program structure as well as in the projects themselves. When the cooperative approach is done well, each person is fully engaged in decisions made within the context of the partnership. In the engineering context, the cooperative relationship instills the importance of listening in order to better integrate the stakeholders into the design process. This in turn challenges the overarching paradigm that engineers are the ones best suited to solve problems, as it encourages greater awareness and recognition that technical expertise is typically only one part of the solution. When a cooperative process is done poorly, complacent partners may be specifically chosen to agree with the programs and/ or the voices of the community are excluded from the process. As a result, the projects may ignore or even reinforce pre-existing injustices or power differentials.

In communal relationships the "we" mentality is expanded beyond the partnership to include the wider community or society. Hence, the level of reciprocity is also expanded to consider the community or the society. For example, the whole community is invited into and relied upon in the design and construction of the project, e.g., through events such as town hall meetings. The process itself recognizes community members as citizens, honoring their human needs and rights, and allowing space for complex relationships with an accompanying awareness of power dynamics and issues of privilege (Lucena, 2013). The interactions and activities within the partnerships provide an avenue for reciprocity, so when individuals put energy into the service-learning experience they are meeting the needs for human connection and community.

When communal partnerships are done well, individuals explicitly recognize and reflect on the value they are bringing to the community, and they have a sense of openness to new opportunities. Yet the communal approach can be done poorly. For instance, Johnson (1983) suggests that privileged individuals may feel a calling to "help" poor or marginalized communities in response to a sense of guilt. Their intention may seem communal if the partnership emphasizes the context of a larger "we," yet some participants are truly doing the project for themselves and not the community (e.g., Carlson, 1995). Without deep reflection and growth among such individuals and the larger program, superficial aid might be the main result.

\section{Theoretical Frameworks: Individual vs. Inter- Organizational Relationships}

One prominent thread running through the findings is linked differences between individual and institutional influences on the nature of partnerships. This corresponds to the two theoretical frameworks within the service-learning literature: Individual Relationships (IR) and Inter-Organizational Relationships (IOR), and points to a number of potential issues and insights that are relevant for both future research and program implementation. To begin, the use of only one type of theoretical framework in research or evaluation studies of service-learning partnerships may limit or mask important findings. For example, research based on an individual relationship framework, such as the SOFAR model (Bringle \& Hatcher, 2012), may overlook significant organizational structures that influence the partnership dynamics. The same is true for organizational theory if a partnership is grounded in individual relationships. Future research should consider and justify use of theoretical frameworks appropriate to the context of the research questions and the partnerships under investigation.

The importance of recognizing the individual and organizational influences is also very important for both program implementation and assessment tools. Being aware of the dominant dynamics while implementing a program can clarify the expectations of the organizations and individuals, and allow proper alignment of the outcomes and evaluation. The desired outcomes and evaluation will depend on this dynamic, and will likely miss important factors if the framework, implementation, and evaluation are not aligned. For example, desired qualities in partnerships such as closeness and care (see Clayton et al., 2010), may be appropriate in a framework grounded in individual relationships, but may have a different meaning or relevance when the organizational structure is a 
dominant dynamic.

\section{Engineering Education Context}

We identify two important elements that the engineering education context contributes to the broader service-learning partnerships literature: projectbased approaches and the engineering mindset. By reflecting on how these contextual factors influenced the partnerships, we add to the discourse of how engineering service-learning programs may situate themselves within the wider servicelearning field, while allowing service-learning programs and partnerships situated in other contexts to further reflect on the transferability of our findings.

To begin, each of the three programs utilized a project-based approach, which is common within engineering (Bielefeldt, Peterson, \& Swan, 2010). These projects tended to go beyond the everyday operational scope and capabilities of many of the partnering organizations, but were identified as important by these organizations. As a result, this dynamic often situated the engineering students as outsiders. One partner who worked with service-learning students from multiple disciplines would keep track of the student hours while they performed operational functions onsite, such as community outreach and education; yet this partner did not consider the engineering projects as operational, thus did not track the associated student hours. Nonetheless, one benefit of this type of outsider dynamic is that many of the partners were personally curious and excited by the project. The project provided new types of interactions, as the partners usually did not work with engineers. As a result, some partners stated that they were personally more engaged in the experience.

The other contextual influence worth noting is the prevalence of the engineering mindset. This mindset has been characterized as the "Engineering Problem Solving" (EPS) approach (Downey \& Lucena, 2006), wherein engineering students are trained to follow a standard procedure to generate a singular numerical solution in response to rarified and decontextualized problem statements. Engineering students often attempt to replicate this approach while working on service-learning projects, seeking a single solution without adequate community input. Each program addressed this issue through training and support designed to help students learn how to bring community voices into the design process. Such efforts are critically important in enabling students to interact with community in ways synergistic with the desired partnership nature.

\section{Limitations and Conclusion}

Case studies, by their nature, are highly dependent on the study context(s). Consequently, variables such as the specific programs, data collection approaches, and researcher's capabilities result in limitations of the study that can be addressed through further research. With regard to the programs, the main consideration for program selection was the presence of well-developed engineering engagement programs that focused on long-term partnerships with organizations within the United States. As a result, there may be structural factors that were not included within this study, yet are highly influential in other programs. This is particularly important for partnerships outside of engineering and those in the context of global service-learning.

With regard to data collection, we triangulated interview data with policy documentation, publications, and informal observations; however, we believe that more in-depth observations, such as ethnographic studies of service-learning partnerships over an extended period, could provide further insights regarding the quality and types of interactions within such partnerships. Another limitation involved the time interval for data collection from Spring 2011 to Spring 2014, during which the first author's knowledge of partnerships and interviewing skills improved. Thus, the interviews at the end offered more depth than the ones at the beginning.

Additionally, the lead author was particularly interested in cooperative and communal partnerships, and therefore tended to favor the CPP program in the initial analysis and write up, thereby potentially biasing her interpretation of the data. We regularly reflected on this subjectivity throughout the interviewing and analysis process, and addressed it by focusing on the empirical evidence, including by consciously focusing our attention on the benefits of transactional partnerships. While future research should take these limitations into account, this study provides a stepping-stone for a variety of possible research projects.

Most generally, we hope that this research spurs and informs critically-engaged research and practice around service-learning partnerships that more explicitly takes into account structural factors and considerations. The findings of this study suggest the value of more intentionally aligning specific program features with the desired partnership natures, while at the same time recognizing the potential influence of both individual and institutional influences. In doing so, service-learning programs with diverse affiliations and missions may be better positioned to serve both participating students and their partner communities.

The findings also present opportunities and im- 
plications specific to the engineering education context. As engineering service-learning programs expand, they will need to build intentional community relationships while at the same time training future engineers to think beyond the traditional engineering problem solving mindset, including by bringing the unique needs and perspectives of community partners into the design process. Furthermore, as the nature of partnerships change, so too does the identity of the engineer and meanings of engineering work. For example, adopting a cooperative or communal approach can encourage participants to see community members as active co-designers. This challenges the dominant image of engineers as domain experts whose interactions with community are typically lop-sided and transactional. Maintaining the vitality and relevance of engineering - and other professions - may increasingly require the crossing and blurring of boundaries between experts and communities, with servicelearning and other engagement programs providing a rich site for exploring this dynamic.

\section{Note}

The authors would like to thank the program administrators, participants, and the first author's committee members (Professors Alice Pawley, William Oakes, and Dwight Giles Jr.) for their support and dedication throughout this study. In addition, we would like to thank the peer reviewers and the Editor for providing valuable feedback on a previous draft of this paper.

\section{References}

Bringle, R. G., \& Clayton, P. H. (2012). Conceptual frameworks for partnerships in service learning. In R. G. Bringle, P. H. Clayton \& J. A. Hatcher (Eds.), Research on service learning: Conceptual frameworks and assessment, Vol. 2 (pp. 539-573). Sterling, VA: Stylus Publishing.

Bringle, R. G., Clayton, P., \& Price, M. (2009). Partnerships in service learning and civic engagement. Partnerships: A Journal of Service Learning \& Civic Engagement, 1(1), 1-20.

Bringle, R. G., \& Hatcher, J. (2002). Campus-community partnerships: The terms of engagement. Journal of Social Issues, 58(3), 503-516.

Bielefeldt, A., Peterson, K., \& Swan, C. (2009). Measuring the impacts of project-based service learning. Paper presented at the American Society of Engineering Education, Austin, TX.

Bielefeldt, A., Paterson, K., \& Swan, C. (2010). Measuring the value added from service learning in projectbased engineering education. International Journal of Engineering Education, 26(3), 535-546.
Carlson, J. (1995). The stranger's eyes. Notes on Anthropology and Intercultural Community Work, 20, 34-38.

Clayton, P. H., Bringle, R. G., Senor, B., Huq, J., \& Morrison, M. (2010). Differentiating and assessing relationships in service-learning and civic engagement: Exploitative, transactional, or transformational. Michigan Journal of Community Service Learning, 16(2), 5-22.

Coyle, E., Jamieson, L., \& Oakes, W. (2005). EPICS: Engineering Projects in Community Service. International Journal of Engineering Education, 21(1), 139-150.

de Graff, E., \& Kolmos, A. (2007). Management of change: Implementation of problem-based and project-based learning in engineering. Rotterdamn, Netherlands: Sense Publishers.

Dedoose Version 6.1.18, web application for managing, analyzing, and presenting qualitative and mixed method research data (2015). Los Angeles: SocioCultural Research Consultants, LLC (www.dedoose.com).

Dorado, S., \& Giles Jr, D. E. (2004). Service-learning partnerships: Paths of engagement. Michigan Journal of Community Service Learning, 11(1), 25-37.

Dorado, S., Giles Jr, D. E., \& Welch, T. C. (2009). Delegation of coordination and outcomes in cross-sector partnerships the case of service learning partnerships. Nonprofit and Voluntary Sector Quarterly, 38(3), 368391.

Enos, S., \& Morton, K. (2003). Developing a theory and practice of campus-community partnerships. In B. Jacoby (Ed.), Building partnerships for servicelearning (pp. 20-41). San Francisco: Jossey-Bass.

Feinstein, N. W., \& Meshoulam, D. (2014). Science for what public? Addressing equity in American science museums and science centers. Journal of Research in Science Teaching, 51(3), 368-394.

Giles, D., \& Eyler, J. (1998). A service learning research agenda for the next five years. In R. Rhoads \& J. Howard (Eds.), Academic service learning: A pedagogy of action and reflection (pp. 65-72). San Francisco: Jossey-Bass.

Giles Jr, D. E., \& Eyler, J. (2013). The endless quest for scholarly respectability in service-learning research. Michigan Journal of Community Service Learning, 20(1), 53-65.

Hatch, J. A. (2002). Doing qualitative research in education settings. Albany, NY: SUNY Press.

Holland, B.A., \& Gelmon, S.B. (1998). The state of the "engaged campus": What have we learned about building and sustaining university-community partnerships. AAHE Bulletin, October, 3-6.

Jacoby, B. (1996). Service-learning in higher education: Concepts and practices. Jossey-Bass.

Jacoby, B. (2003). Fundamentals of service-learning partnerships. In B. Jacoby (Ed.), Building partnerships for service-learning (pp. 1-19). San Francisco: Jossey-Bass.

Janke, E. M. (2009) Defining characteristics of partnership identity in faculty-community partnerships. In B. E. Moely, S. H. Billig \& B.A. Holland (Eds.), Creating our identities in service-learning and community 
engagment (pp. 75-101). Charlotte, NC: Information Age.

Janke, E. M. (2012). Organizational partnerships in service learning: Advancing theory-based research. In R. G. Bringle, P. H. Clayton \& J. A. Hatcher (Eds.), Research on service learning: Conceptual frameworks and assessment, Vol. 2B (pp. 384-426). Sterling, VA: Stylus Publishing.

Johnson, P. (1983). A history of the modern world: From 1917 to the 1980s. London: Weidenfeld and Nicolson.

Litchfield, K., \& Javernick-Will, A. (2015). "I am an engineer AND": A mixed methods study of socially engaged engineers. Journal of Engineering Education, 104(4), 393-416.

Lima, M. (2013). Building playgrounds, engaging communities: Creating safe and happy places for children. Baton Rouge, LA: LSU Press.

Lucena, J. (2013). Engineers and community: How sustainable engineering depends on engineers' views of people. In J. Kauffman \& K. M. Lee (Eds.), Handbook of sustainable engineering (pp. 793-815). The Netherlands: Springer.

Lucena, J., Schneider, J. J., \& Leydens, J. A. (2010). Engineering and sustainable community development (Vol. 11). San Rafael, CA: Morgan \& Claypool Publishers.

Mashek, D., Cannady, L. W., \& Tangey, J. P. (2007). Inclusion of community in self scale: A single-item pictorial measure of community connectedness. Journal of Community Psychology, 34(2), 257-275.

McCahan, S., Ault, H. K., Tsang, E., Henderson, M. R., Magleby, S. P., \& Soisson, A. (2012, June). A multidimensional model for the representation of learning through service activities in engineering. Paper presented at the American Society for Engineering Education, San Antonio, TX.

National Academy of Engineering (2005). Educating the engineer of 2020: Adapting engineering education to the new century. Washington, DC: National Academies Press.

Nieusma, D., \& Riley, D. (2010). Designs on development: Engineering, globalization, and social justice. Engineering Studies, 2(1), 29-59.

Patton, M. Q. (2002). Qualitative research \& evaluation methods (3rd ed.). Thousand Oaks, CA: Sage Publications.

Phillips, J. T., \& Ward, C. V. (2009). Two-dimensional approach for assessing transformative campus/community service-learning partnerships. In S. Billig \& B. Holland (Eds.), Creating our identities in servicelearning and community engagement (pp. 103-127). Charlotte, NC: Information AgePublishing.

Reynolds, N. P. (2014).What counts as outcomes? Community perspectives of an engineering partnership. Michigan Journal of Community Service Learning, 21(1), 79-90.
Sandy, M., \& Holland, B. (2006). Different worlds and common ground: Community partner perspectives on campus-community partnerships. Michigan Journal of Community Service Learning, 13(1), 30-43.

Sockett, H. (1998). Levels of partnership. Metropolitan Universities: An International Forum, 8(4), 75-82.

Schneider, J., Lucena, J., \& Leydens, J. A. (2009). Engineering to help: The value of critique in engineering service. IEEE Technology and Society Magazine, 28(4), 42-48.

Shenton, A. K. (2004). Strategies for ensuring trustworthiness in qualitative research projects. Education for Information, 22(2), 63-75.

Shuman, L. J., Besterfield-Sacre, M., \& McGourty, J. (2005). The ABET "professional skills" - Can they be taught? Can they be assessed? Journal of Engineering Education, 94(1), 41-55.

Sheppard, S. D., Macatangay, K., Colby, A., \& Sullivan, W. (2009). Educating engineers: Designing for the future of the field. San Francisco: Jossey-Bass.

Stoecker, R., \& Tryon, E. A. (2009). The unheard voices. Philadelphia: Temple University Press.

Thompson, J. (2015). Engineering community engagement partnerships: Investigating motivation, nature, and structure (Doctoral dissertation, Purdue University). Retrieved from ProQuest (3720049).

Tucker, B. G., Kazmer, D. O., Bielefeldt, A. R., Paterson, K., Pierrakos, O., Soisson, A. et al. (2013). Principles of sustaining partnerships between higher education and their larger communities: Perspectives from engineering faculty engaged in learning through service [Special issue]. International Journal for Service Learning in Engineering, Humanitarian Engineering and Social Entrepreneurship, 48-63.

Vaz, R. (2011). Crossing borders: My journey at WPI. In G. L. Downey \& K. Beddoes (Eds.), What is global engineering education for? The making of international educators. San Rafael, CA: Morgan \& Claypool Publishers.

Vanasupa, L., \& Schlemer, L. (2014, June). Relational versus transactional community engagement: An experience of the benefits and costs. Paper presented at the American Society of Engineering Education, Indianapolis, IN.

Vanasupa, L., Schlemer, L., Burton, R., Brogno, C., Hendrix, G., \& MacDougall, N. (2014). Laying the foundation for transdisciplinary faculty collaborations: Actions for a sustainable future. Sustainability, 6(5), 2893-2928.

Worrall, L. (2007). Asking the community: A case study of community partner perspectives. Michigan Journal of Community Service Learning, 14(1), 5-17.

Yin, Robert K. (2002). Case study research: Design and methods. Sage Publications. 
Authors

JULIA D. THOMPSON (julia.thompson@sjsu. edu) is currently working to develop and support San Jose State University's EPICS program and conducting post-doctoral research with the University of Illinois Champaign-Urbana to investigate misconceptions in cybersecurity education. She is a recent Pickett Fellow, working with homeless and low-income youth to design and build an outdoor community art space in Berkeley, CA. She obtained her Ph.D. in Engineering Education from Purdue University and a B.S. in Chemical engineering from UC Berkeley. Her primary research interests include engineering community partnerships, spirituality in engineering, and global engineering education.
BRENT K. JESIEK (bjesiek@purdue.edu) is associate professor in the Schools of Engineering Education and Electrical and Computer Engineering at Purdue University. He leads the Global Engineering Education Collaboratory (GEEC) research group, and is the recipient of an NSF CAREER award to study boundary-spanning roles and competencies among early career engineers. He holds a B.S. in Electrical Engineering from Michigan Technological University and M.S. and Ph.D. degrees in Science and Technology Studies (STS) from Virginia Tech. He draws on expertise from engineering, computing, and the social sciences to advance understanding of geographic, disciplinary, and historical variations in engineering education and practice. 


Theme and Description $\quad$ EPICS GPP-US CPP

Learning Outcomes - Rigor and clarity of the outcomes

Deliverables - Are deliverables required, and what is the quantity and quality expected?

Assessment - Is the assessment rigorous and aligned with the outcomes and deliverables?

Civic Outcomes - Are students expected to reflect on the civic element? Is this included in assessment?

Curricular Position - Is the experience extracurricular, elective, or required?

Group Characteristics - Are the teams interdisciplinary? How large are the teams?

Size of the Program - Number of students, administrative support, and faculty engagement.

Geographical Context - Is the service local or global?
Rigorous and well defined learning outcomes in syllabus that aligned with accreditation criteria

Assignments and reflection are required. Projects can roll over from terms and are delivered to the partner when they are completed.

Rigorous and aligned: Well defined learning outcomes and assessment rubrics to determine if learning objectives were met.

There is a self-reflective element in the journals, where students are required to reflect on the needs of the project partner.

An elective course that can also meet requirements in some departments.

Teams are 8-24 students, with smaller project teams (3-5).

The teams are interdisciplinary and vertically integrated (across academic levels).

There are over 800 students annually, full-time administrative support, and faculty members can oversee teams.

Focuses primarily on local, and Focuses on global, and has has some global partnerships. The focus is on local partnerships in this study.

Duration - Is the partnership for a short amount of time or over the length of years?

Partnerships are long-term, as the commitment to EPICS is expected to last multiple years.

Interaction - Is there little engagement with the partner or a full immersive experience?

Technical Content - Is there technical content within the project, and if so, how complex?

Engagement level varies based on the students and the partner. There are set design reviews for the external partners to engage in the work.

The students design a product for the partnering organization. Technical content is present; complexity varies based on product.

Social Content - Is there a social element within the project, and if so, how complex?
Rigorous and well defined learning outcomes in syllabus that aligned with accreditation criteria

Assignments are required. A final report with an oral presentation to the partner is due at the end of the term.

Rigorous and aligned: Well defined learning outcomes and assessment rubrics to determine if learning objectives were met.

This is not currently required, but there was discussion about including a required reflection component.

An optional program that meets a graduation requirement for juniors.

Team are 3-4 students and interdisciplinary. All students have junior standing. There are 4-6 teams assigned to a given project center.

There are about 500 students annually, full time administrative support, and the faculty members can oversee teams.

local partners as well. In this study, the focus is on partnerships in the Eastern United States.

Partnerships only have a single term expectation, but many recur. There is a deliverable to the client at the end of the 14week timeframe.

Engagement is an immersive seven-week experience where students work full-time, onsite of the partner organization.

The project is a socio-technical project. It can vary in technical content based on the project.

The social content is the main purpose of the experience.
Rigorous and well defined learning outcomes in syllabus that aligned with accreditation criteria

Assignments and reflections are required. Final reports are reviewed by design team before implementation.

Rigorous and aligned: Well defined learning outcomes and assessment rubrics to determine if learning objectives were met.

There is a self-reflective element required where the students are reflecting on how they designed for the soul of the community.

A required course for all firstyear Biological Engineering (BE) students.

Teams are 3-4 Biological Engineering students.

There are around 85 students in three classes, a design team of advanced students, and a faculty member with support from a service-learning center.

All the partnerships are local and within the East Baton Rouge Parish (school district).

There are many partnerships that are ongoing. The LSU students work with an elementary school for a single semester.

The LSU students engage with the elementary students multiple times through a semester, and do the design work independently.

The technical content focuses on the structural components and safety related to playground design.

The social dimensions are within the project.

*The information in this table reflects the program characteristics at the time of data collection (2011-2014) 
1. History

a. Personal and professional background

i. What is your title/role within your organization?

ii. What is your educational and professional background, including how you got involved with this organization?

b. How did you and/or your organization get involved with [the EPP]?

c. Why did you and/or your organization partner with [the EPP]?

d. What is your role within the partnership?

2. Projects

a. What projects have you work on with [the EPP]? Examples

b. What are typical successes and failures? Why

c. How do [the EPP] students get background information about your organization and the project(s) they work on?

d. What things do you feel are most important to tell students each semester as they are introduced to the partnership?

e. What could be done to better orient students to your organization and the project(s) they work on?

f. What is your interaction like? With students? With faculty members? With teacher assistants?

3. Project relational dynamics

a. What have you been satisfied with regarding the students' ability to understand the needs of your organization and the goals of the project(s)? Why or why not? Any specific examples?

b. How are decisions made within the project(s), such as which project students should work on, what materials are used, etc.?

c. Do you feel like your voice is heard on the projects? Why or why not? Any specific examples?

d. What were your expectations of EPICS projects when you first started working with EPICS, including student capabilities, useful project deliverables, benefits to your organization, etc.

e. How have your expectations changed over time?

4. Motivation

a. What do you like about working with [the EPP]? Examples

b. What do you find difficult about working with [the EPP]? Examples.

c. What resources do you allocate to [the EPP] personally and from the organization?

d. If you were not involved in the [the EPP] partnership, how would your resources be spent? Personally? The organization?

e. What are the benefits from working with [the EPP]? Personally? The organization?

f. Are the benefits greater than the costs? Personally? The organization?

g. Do you find value in the partnership?

h. How do you view the long-term partnership model?

5. Students

a. What do you think the students gain from the project(s)?

b. What do you see as students' most difficult hurdle, during any phase of the project(s)?

c. How do you view the [the EPP] students' feelings toward the project(s)?

d. How do you view the [the EPP] students' feelings toward your organization?

e. What do you see as the students' strengths and weaknesses?

f. What are common attributes of the students working with [the EPP]?

g. What do you hope the students achieve?

6. Overall

a. Who benefits from the [the EPP] partnership? Why?

b. Have you worked with other volunteers/service-learning groups?

i. How does [the EPP] compare?

c. What would you like to change about the [the EPP] program? 